\title{
Relationship Between Native Language And English Language Acquisition: The Case Of Meranaw Learners Of English
}

\author{
Mujahidah D. Guimba \\ Pantao Ragat Agro-Industrial High School, \\ Lanao del Norte, Philippines
}

\section{Hamidah H. Hadji Faisal}

Asst. Prof. Norhayna Eryll Madale-Unte

College of Education, Mindanao State University-Marawi, Marawi City, Philippines

\author{
Dr. Wardah D. Guimba \\ College of Education, Mindanao State University-Marawi, \\ Marawi City, Philippines
}

\author{
Jerryk C. Alico \\ MSU-Marawi Senior High School, Mindanao State University-Marawi, \\ Marawi City, Philippines
}

\begin{abstract}
The issue surrounding the relationship between the L1 and L2 has been of great interest among researchers for decades (Cui, n.d.). The newly implemented K+12 Curriculum in the country is also leaning on the proposition that $\mathrm{L} 1$ proficiency has a facilitative effect towards second language acquisition among learners. In view of that, the purpose of this study focuses on determining the relationship between $\mathrm{L} 1$ and $\mathrm{L} 2$ which are Meranaw and English, respectively, in terms of vocabulary skills in the case of fourth year high school students in MSU-UTC. The correlation made use of their scores on the tests that measured their linguistic skill in both languages. The results revealed that most of the respondents are proficient in their native language in terms of synonyms, antonyms, and most especially, context clues. Moreover, respondents with good performance in the English language test also had the largest number. In view of these results, it is inferred that the respondents' native language proficiency is directly and significantly related to their English language acquisition, which is also supported by the hypothesis tests conducted $(p<0.05)$. In other words, as native language proficiency increases, English language proficiency also increases. It is recommended that teachers of the recent $\mathrm{K}+12$ Curriculum should properly implement the stipulations of the language curriculum, with the adequate assistance of the government and other authorities, in order to see the positive results of $L 1$ usage in assisting English language acquisition. Conducting further studies is highly encouraged to continually advance knowledge regarding $\mathrm{L} 1$ and $\mathrm{L} 2$ relationship.
\end{abstract}

Keywords: Language acquisition, English language, native language, secondary school, K to 12 curriculum 


\section{INTRODUCTION}

This research has its focal point primarily placed on the investigation of the relationship between the native language and the second language acquisition. Out of the interest of the researchers, reinforced by the positions of empirical researchers regarding the issue, this study is proposed to affirm the findings of previous studies (e.g. Liu, 2008; Bossers, 1991; Nikolov \& Csapo, 2010). Moreover, this was conducted due to the new curriculum implemented by the Department of Education which requires the use of the mother language as medium of instruction in teaching primary education from Kindergarten to Grade 3. It is believed that once the learners have acquired their native language, there is a possibility that they will find second language acquisition easy, whether it is Filipino or English language.

Language, according to Brown (1994), is a natural function of human development. Except in every rare case, people are continually surrounded by their native language and have constant opportunity to use and practice it (Cummins, Miramonte, \& Nadeau, 1997). Language acquisition is one of the most important and fascinating aspects of human development. The first sound a new born baby makes is in the form of 'coos' and 'gurgles' which elders find pleasing to hear. These are the indications which a small child shows to have something. Various language variables are involved in the language processes like phonology, vocabulary, morphology, syntax, paralinguistic, pragmatics and discourse. In order to provide success in cognitive functioning as well as professional life of an individual, his/her first language acquisition must develop strongly in the early years (Banerjee, Sinha, Sinha, and Shastri, 2009).

Language plays a central role in education. Children learn through language by listening, reading, speaking and writing. If they begin school in language that they know well-the language they speak at home often referred to as the mother tongue, they can understand what is being taught and can learn the official or national language used at higher levels of education in their area (CALP, n.d).

First-language acquisition is a complex process that linguists only partially understand. Young children have certain innate characteristics that predispose them to learn language. These characteristics include the structure of the vocal tract, which enables children to make the sounds used in language, and the ability to understand a number of general grammatical principles, such as the hierarchical nature of syntax. These characteristics, however, do not predispose children to learn only one particular language. Children acquire whatever language is spoken around them, even if their parents speak a different language. An interesting feature of early language acquisition is that children seem to rely more on semantics than on syntax when speaking. The point at which they shift to using syntax seems to be a crucial point at which human children surpass apes in linguistic ability.

First language is being termed by different names such as native language, primary language and mother tongue (e.g. Meranaw). This language is assumed to be one which is acquired during early childhood- starting before the age of about 3 years. Acquisition of more than one language during early childhood leads to simultaneous multilingualism (Banerjee et al., 2009).

Although second language acquisition literally refers to learning a language after having acquired a first language, the term is frequently used to refer to the acquisition of a second language after a person has reached puberty. Whereas children experience little difficulty in acquiring more than one language, after puberty people generally must expend greater effort to learn a second language and they often achieve lower levels of competence in that language. Thus, the researchers chose to conduct on fourth year students because they are in puberty stage (Comrie, Bernard, \& Redmond, 2008). 
Particularly, this study was interested to determine whether or not there is a relationship between the native language of the Meranaw students and their second language acquisition (English). This research is conceptualized due to the dearth of literature and studies about the relationship between English and Meranaw languages. Thus, the researcher is interested to forward an essential reference to this matter. Although only few resources were found regarding the relationship between the aforementioned languages, adequate theories and propositions clarified this phenomenon.

These languages, in the first place, are not etymologically related unlike English and Latin or French. In fact, as mentioned by Nikolov and Csapo (2010), a number of studies have supported the interdependence across a variety of languages, though lower correlations have been found between linguistically distant languages such as Chinese to English and Turkish to Dutch. On the other hand, closely related languages like what is mentioned are found to have the opposite correlation. In that view, this study founded a novel idea on the significance of the relationship between the Meranaw language and English language acquisition.

Mentioned in Bismilla (2010), Cook (2003) suggested that the L1 and L2 are interwoven in the L2 user's mind in vocabulary, syntax, phonology and pragmatics. He added that since the first language and other language or languages are in the same mind, they must form a language super-system at some level rather than be completely isolated systems. Yamashita (2002) has added a dichotomy of influence of L1 on L2. Accordingly, the interdependence of abilities in two languages can be revealed in the "process" of reading and in the "product", which made up the two types of studies namely process-oriented and product-oriented. This study applied the product-oriented study. Basically a test-based quantitative research, test scores of the students in native and second language was used as representations of their ability. Tests such as synonyms, antonyms, and contextual clues were given to them, both in Meranaw and English.

\section{LITERATURE REVIEW}

Cummins' Linguistic Interdependence Hypothesis argues that certain first language (L1) knowledge can be positively transferred during the process of second language (L2) acquisition. The L1 linguistic knowledge and skills that a child possesses can be extremely instrumental to the development of corresponding abilities in the L2. An integral component of these facilitative aspects of language influences is that the L1 be sufficiently developed prior to the extensive exposure to the L2 as would be found, for example, in an educational environment (Vrooman, 2000). It suggests that growth in a second language is dependent upon a well-developed first language, and that children's first language skills must become welldeveloped to ensure that their academic and linguist performance in the second language is maximized.

The linguistic interdependence hypothesis claimed that L1 linguistic knowledge and skills that a child possesses is an instrument in the development of corresponding abilities in L2, with the proposition that L1 should be adequately developed prior to the extensive exposure to L2. Once a set of language operations such as reading and writing is acquired, the same operations will be available as needed within L2 contexts. The term 'common underlying proficiency' (Cummins, 2000) refers to cognitive academic proficiency underlying performance in both languages and the interdependence hypothesis states that proficiency transfer from one language to the other will occur provided there is adequate exposure to L2 in school as well as in the environment, and adequate motivation to learn it. This means that the linguistic, metalinguistic and literacy knowledge and skills students have learned in their L1 will bear on the learning of academic knowledge and skills in L2 (Cummins, 2000 as cited by Nikolov \& Csapo, 2011). 
As finally noted by Cummins (2000), students will transfer aspects of linguistic and conceptual knowledge from one language to another in input (reading, listening) and output (speaking, writing). He suggested that depending on the sociolinguistic situation, five types of transfer are possible: (1) transfer of conceptual elements, (2) transfer of metacognitive and metalinguistic strategies, (3) transfer of pragmatic aspects of language use, (4) transfer of specific linguistic elements, and (5) transfer of phonological awareness - the knowledge that words are composed of distinct sounds (cited by Bismilla, 2010).

Another component of Cummins' theory is the BICS/CALP (Basic Interpersonal Communication Skills/Cognitive Academic Language Proficiency) continuum. These terms are commonly used in discussion of bilingual education and arise from the early work of Cummins in which he demonstrated his ideas about the two principal continua of second language development in a simple matrix. BICS describes the development of conversational fluency in the second language, whereas CALP describes the use of language in decontextualized academic situations.

The BICS are the "surface" skills of listening and speaking which are typically acquired quickly by many students; particularly by those from language backgrounds similar to English who spend a lot of their school time interacting with native speakers (ESL-FIL website, n.d.). It describes the development of conversational fluency in the second language. BICS is said to occur when there are contextual supports and props for language delivery. Face-to-face context embedded situations provide, for example, non-verbal support to secure understanding. Actions with eyes and hands, instant feedback, cues and clues support verbal language.

The CALP, as the name suggests, is the basis for a child's ability to cope with the academic demands placed upon her in the various subjects. Cummins states that while many children develop native speaker fluency (i.e. BICS) within two years of immersion in the target language, it takes between 5-7 years for a child to be working on a level with the native speakers as far as academic language is concerned. CALP is said to occur in context reduced academic situations. Where higher order thinking skills (e.g. analysis, synthesis, evaluation) are required in the curriculum, language is disembedded from a meaningful, supportive context. Where language is disembedded the situation is referred to as context reduced (Baker, 2006).

Another theory of Cummins as cited by Mascara (2012) is the Threshold Hypothesis which states that a minimum threshold in language proficiency must be passed before a second language speaker can reap any benefits from language. It also states that in order to gain proficiency in a second language, the learner must also have passed a certain and age appropriate level of competence in his or her first language (Wikipedia website). It assumes that a child needs to achieve a certain level of proficiency or competence in the first or second language to take advantage of the benefits of bilingualism.

This hypothesis posits that if there is a low level of competence in both languages there may be negative consequences. Sometimes this has been referred to as semi-lingualism, but this term and description is not often used nowadays. It would seem that there needs to be a minimum level of linguistic and conceptual knowledge in the first language to successfully add a second and develop bilingually. This threshold hypothesis cannot be defined in absolute terms, rather it is a theoretical description, but it can help in explaining the development of bilingual learners. It also supports the arguments for the benefits of additive bilingualism and bilingual education. 
There is a wealth of researches existing in the area of first and second language relationship, conducted at different locales, involved diverse participants with distinct tongues. These provide thoughtful insights which helped in the specification of the variables and paradigm of this study. Studies reviewed herein essentially answer the question as to how first language is integrally related to the second language.

Various studies around the world indicate that when pupils learn to read and write in their mother tongue before learning to read and write in a second or third language, they progress more quickly both in literacy skills and in second language acquisition (Dumatog \& Dekker, 2003 as cited by Gran and Plaza, 2013). According to UNESCO, years of research have shown that children who begin their education in their mother tongue make a better start, and continue to perform better than those who start at school with a new language. In addition, Gonzales (2003) said that using the mother tongue first for the development of efficient basic and functional literacy skills should enable learners to build on and transfer these skills to the second language (Gran \& Plaza, 2013)

Several studies have shown that English speaking learners of Spanish have difficulty producing the reduced aspiration of Spanish voiceless stops. Gonzalez-Bueno (1997) examined Intermediate Spanish students in the university setting and confirmed this initial difficulty, although she also showed that explicit pronunciation instruction could help them overcome these problems. Similarly, Flege (1980) investigated the ability of Saudi learners of English to produce sounds in their L2 and whether they experienced interference from the L1 in doing so. His findings confirmed the influence of L1 in L2 phonology, the word-final and initial Voice Onset Time (VOT) values of participants were similar to their L1.

According to Bhela (1999) the second language learning environment encompasses everything the language learner hears and sees in the new language. It may include a wide variety of situations such as exchanges in restaurants and stores, conversations with friends, reading street signs and newspapers, as well as classroom activities, or it may be very sparse, including only language classroom activities and a few books. Extensive research has already been done in the area of native language interference on the target language. Dulay et al. (1982) define interference as the automatic transfer, due to habit, of the surface structure of the first language onto the surface of the target language. Lott (1983) defines interference as errors in the learner's use of the foreign language that can be traced back to the mother tongue (Bhela, 1999).

In addition, Tucker (2002) as cited by Gran and Plaza (2013) agrees that the development of the mother tongue is important for cognitive development and as a basis for learning the second language. Furthermore, Carroll (1964) argues that the circumstances of learning a second language are like those of a mother tongue. Sometimes interferences and occasionally responses from one language system will intrude into speech in the other language. According to Faerch and Kasper (1983), it appears that learning is most successful when the situations in which the two languages (native language and second language) are learned, are kept as distinct as possible. To successfully learn second language requires the learner to often preclude the native language structures from the second language learning process, if the structures of the two languages are distinctly different (Bhela, 1999).

Beardsmore (1982) suggests that many of the difficulties a second language learner has with the phonology, vocabulary and grammar of second language are due to the interference of habits from first language. The formal elements of first language are used within the context of second language can result errors in second language, as the structures of the languages, first 
language and second language are different (Bhela, 1999). In addition, Bhela (1999) stated in his case study about the interference of native language to the second language, the use of first language structures as a principle of fundamental language organization and processing has immediate serviceability for these learners. The learners bring the form and meaning of both first language and second language into closer alignment and thus render usable a complex portion of second language syntax that would otherwise be for the time being, inaccessible to them. The prior disposition of first language has affected the second language responses.

Blum-Kulka and Levenston (1983) contend that all second language learners begin by assuming that for every word in L1 there is a single translation equivalent in L2. The assumption of word for- word translation equivalence or 'thinking in the mother tongue (L1)' is the only way a learner can begin to communicate in a second language (Bhela 1999). In addition, McLaughlin (1987) as cited by Gran and Plaza (2013) states that program using the mother tongue as a medium of instruction inside the classroom in the early grades will hasten the basic communication skills of the pupils. When pupils develop fluency in speaking, reading and writing in the first language, the L1 can then be utilized as a bridge or transitional to learning the L2 and L3 (e.g. Filipino, English and Arabic). The introduction of languages in this program will give pupils confidence in learning academic concepts.

In the conclusion of Bhela (1999), it is indicated that second language learners have adopted their first language structures to help them in their second language texts. These learners will not attain mastery of the target language as long as the process of translation equivalence is in place. Blum-Kulka and Levenston (1983) assert that mastery of the second language involves the gradual abandonment of the translation equivalence, the internalization of the syntactical structures in second language independently of the first language equivalent, and the ability to 'think in the second language'. These learners have accumulated structural entities of second language but demonstrate difficulty in organizing this knowledge into appropriate, coherent structures. There is a significant gap between the accumulation and organization of this knowledge. When writing in the target language, these learners rely on their native language structures to produce a response, as shown in this study. As the structures of first language and second language have differences, there has been a relatively high frequency of errors occurring in the target language, thus indicating an interference of the native language on the target language, as expected.

The study of Barrios and Bernardo (2012) investigated the proposition that the acquisition of case markings rules in groups of L2 Filipino learners would be affected by the similarity or difference in the actancy structure of L1, which is either Cebuano or Chavacano and Filipino. Reid and Liao (2004) provide a comprehensive description of transitivity and ergativity of Philippine languages, and this description indicates that most Philippine languages, Filipino and Chavacano included, are morphologically ergative languages. However, Chavacano seems to be one of the exceptions in that. It seems to be morphologically accusative language (Forman, 2001; Nolasco, 2005).

Most precedent researches to be reviewed are those that gave evidences on the major theories used in this study which are the linguistic threshold hypothesis and linguistic interdependence hypothesis. Firstly, studies investigating the existence of linguistic threshold had endeavored to overcome methodological shortcomings as what Anderson (1984) had noted. Several carefully conducted studies reported the relationship between two languages such as Bossers' (1991), Carrel's (1991), Lee and Schalert's (1997) and many others. These studies discovered information on three variables (L1 reading, L2 reading, and L2 proficiency) from the same 
individuals, examined the relationship between the variables, and presented evidence that can support LTH (Cui, n.d.).

Bossers (1991), in his study involving Turkish learners of Dutch, had found out that L1 reading and L2 proficiency contributed significantly to L2 reading. L1 reading ability was reported to become more significant once a relatively high level of L2 proficiency has been obtained which lends support to LTH. In addition, Carrell (1991) accounted the factors that comprise reading comprehension and its evaluation. It studied two groups namely Spanish learners of English and English learners of Spanish. For the two groups, L1 reading and L2 proficiency were found to contribute significantly to L2 reading. For foreign language learners, L2 proficiency was a better predictor of reading performance than did L1 reading ability. Moreover, L1 reading ability was a better predictor than L2 proficiency for second language learners. Carrell then recognized the different learning environments of the learners that may have caused this difference. Lastly, he interpreted that L2 reading is more a language problem at the low L2 proficiency level which is aligned to Anderson's (1984) conclusion.

In continuation to this interesting research endeavor, Lee and Schalert (1997) investigated Korean learners of English to observe if there is an existing relationship between L1 reading, L2 reading, and L2 linguistic knowledge. Their findings indicated that both L1 reading ability and L2 proficiency contributed significantly to L2 reading ability. In addition, Taillefer's (1996) study added more understanding of this relationship through considering more cognitively demanding tasks, scanning and reading for meaning. He disclosed that both L1 reading ability and L2 proficiency affect significantly foreign language reading comprehension with variation in different tasks.

Schoonen, Hulstijn, and Bossers (1998) as well studied the predicting variables of L2 reading ability with 274 eighth- and tenth-grade Dutch EFL students. They reported that L1 and L2 reading initially had a strong relationship sharing $40 \%$ variance. However, as they accounted for L2 vocabulary and metacognitive knowledge, they concluded that these variables were stronger predictors of L2 reading ability than L1 reading ability.

Also, several studies examining L1 and L2 relationship in reading gave support to the linguistic interdependence hypothesis. As cited by Jiang (2011), classic researches done by Bernhardt and Kamil, Cummins, Van Gelderen, et al., Verhoeven and the like put forward foundational ideas regarding the matter. Recently, Nikolov and Csapo (2010) conducted a study regarding the relationship between reading skills in early English as a foreign language and Hungarian as a first language. Using sixth- and eighth-grade students, they found out that significant connections have been found between L1 and L2 reading performances indicating that the reading skills in the two languages interact with one another. Moreover, the relationships between L1 reading and L2 reading scores were weaker compared to those between L2 reading and other L2 skills. This signifies that students with scores higher in one L2 skill tend to perform better in other L2 skill areas.

Another relevant study on the mutual compensation between L1 reading ability and L2 language proficiency in L2 reading comprehension was made possible by Yamashita (2002) in the context of 241 Japanese EFL learners. Still, results indicated that both L1 reading ability and L2 language proficiency contribute to L2 reading comprehension, but the effect of L2 language proficiency is stronger than that of L1 reading ability. Furthermore, results also demonstrated the existence of mutual compensation between L1 reading ability and L2 proficiency. 
In the report of Bournot-Trites and Tallowitz (2002), they made mentioned about various studies which underwent investigations regarding the relationship between L1 and L2. First is Marsh's research that compared students who were instructed in Chinese with students who received instruction in English, and found that the achievement in the first language (Chinese) and second language (English) were enhanced using English instruction. Thus, intensive instruction in a second language did not hinder the development of the first language. Another one is Genesee's study which reported high correlations between L1 and L2 reading skills, and concluded that this proficiency is most probably transferred from one language to the other.

Additionally, as Mayberry and Lock (2003) introduced, one significant query pertaining to language acquisition is the magnitude to which age constraints its outcome, "otherwise known as a sensitive or critical period (CP) of language." (p.369). Hence, age as well has been an investigated variable in language acquisition. One study was that of Birdsong and Molis's (2001) which found out that age of L2 acquisition did not correlate with grammatical outcome between the ages of 3 and 15. According to them, many L2 learners performed within the range of the native English speakers, a manifestation of ceiling effects.

Mayberry (1993), as cited by the above mentioned study, did research on whether age constrains are greater for the outcome of L1 as compared to L2, with deaf adults as participants. It was discovered that L2 learners' grammatical performance was significantly higher and different from that of learners with no early language experience on a task requiring recall of complex American Sign Language sentences.

\section{HYPOTHESES}

The following hypotheses were tested using 0.05 level of significance:

Ho1: There is no significant relationship between the respondents' native language and their English language acquisition in terms of Synonyms.

Ho2: There is no significant relationship between the respondents' native language and their English language acquisition in terms of Antonyms.

Ho $_{3}$ : There is no significant relationship between the respondents' native language and their English language acquisition in terms of Contextual Clues.

\section{Research Design}

\section{METHODOLOGY}

This study used the descriptive-correlation research design. It is primarily descriptive in nature in the sense that it involves fact finding with adequate interpretation, particularly, a survey type research. As used in this study, descriptions were firstly made for the profile of the respondents according to age, gender, languages able to speak, and their parents' tribe. Also, their linguistic performance in L1 (Meranaw) and L2 (English) was also described based on the scores they had in the tests. The correlation design was employed to determine the significance of the relationship between the independent variable which is the respondents' L1 performance and the dependent variable represented by their L2 performance. Implications were then drawn from the findings. Lastly, the hypotheses raised in this study were tested.

\section{Participants of the Study}

The location where the study was conducted is the Mindanao State University-University Training Center (MSU-UTC) Experimental Campus located in the Islamic City of Marawi City, Lanao del Sur, Philippines. Marawi City is predominantly inhabited by an ethnic Muslim tribe called Meranaw whose language is also named the same which is a member of the MelayoPolynesian languages. With the advent of mainstream education in the Lanao province in early 
$20^{\text {th }}$ century, the Meranaw people have been taught Filipino, the national language, and English through schools with integrated curricula.

The selection of the participants in this study was decided out of what is common among students in terms of grade level as used by previous studies. Some used fourth and eighth grade students (Nikolov \& Csapo, 2010), ninth and tenth grade (Lee \& Schalert, 1997), eighth and tenth grade, adolescents in general, and even college students (Liu, 2008). Common among them is that the respondents are adolescents with age ranging from 11 to 16 or 17 years old. Tenth grade students, or fourth year high school in the Philippines, who are expected to be 16 to 17 years old, were preferred by the researchers. These students of MSU-UTC were enrolled during the school year 2013-2014. Also, the researchers chose MSU-UTC students because they themselves were students teachers assigned in the said school and specific year level. Basically, the researchers purposively chose fourth year students and then used random sampling technique to select the specific students to represent as samples of the total population of the fourth year level. Originally, there were one hundred fifty (150) students gathered randomly. However, during the data collection period, three of the chosen samples were not present, so that one hundred forty-seven (147) students were left as the final respondents.

\section{Instrument and Its Validity}

The instrument used in gathering of data is composed of three parts. The first part covered the inquiry on the respondents' information in terms of age, gender, languages they are able to speak, and their parents' tribe. In filling up this part, respondents put a check mark on the spaces provided which represent the options that were true about their profile. The second part deals with the performance of the respondents in their native language (Meranaw language) in terms of synonym, antonym and contextual clues. This test was structured by the researchers themselves and was pilot tested for internal consistency. After the analysis, it was found out that the Cronbach's alpha is 0.700 or $70.0 \%$. As what Nunnaly and Bernstein (1999) stated, a reliability of $70 \%$ and above for the whole instrument is acceptable.

The third part deals with the performance of the respondents in second language (English language) in terms of synonym, antonym and contextual clues. The questions were extracted from the thesis of Ismael and Maruhom (2013) entitled, "The Vocabulary Skills and Learning Strategies of Senior Students of MSU-UTC", with a reliability of 0.808 or $8.08 \%$. This also means that the instrument's reliability is acceptable.

The researchers also conducted an informal interview, asking the respondents about their opinions and insights regarding the role of the Meranaw language in their acquisition of the English language. This was for the purpose of gathering first-hand information about the personal experiences of the respondents, particularly in the use of the Meranaw linguistic knowledge in learning the English language. Thus, it was to cross-check as well the quantitative data gathered using the questionnaire.

\section{Data Gathering Procedures}

The data gathering procedures accomplished in this study were in twofold: one was the information-seeking and pilot testing procedure while the other is the data collection proper. As made mention, a pilot test of the test questionnaires was conducted to ensure a reliable instrument. A group of 50 fourth year Meranaw-speaking students in MSU-UTC were requested to answer the tests and their average time in answering the tests was also determined. After they answered, the tests were treated for analysis, so then the reliability computation followed. As mentioned in the previous section of this chapter, the tests were found reliable. Thus, the data collection proper was formally done. 
Prior to the data collection, communication seeking for permission to conduct the study was delivered to the director of MSU-UTC. After being permitted, the schedule of data collection was settled. The selection of the respondents was also conducted. When the respondents were already identified, they were first oriented about the study and were given some reminders regarding the tests. The identified average time during the pilot test was 45 minutes which was also implemented as time allotment for the data collection proper. Immediately after taking the tests, the questionnaires were retrieved and subjected to statistical analysis.

\section{Statistical Tools Used}

The following statistical tools were used to treat the data gathered from the instruments:

1. Frequency and Percentage Distribution - This descriptive statistical tool was used to describe the respondents in terms of their age and gender by tallying the number of respondents belonging to a certain category of the variables and calculating the portion they constituted. The data are in the form of a frequency and percentage distribution table.

2. Mean - This tool was used to compute for the calculation of the average scores of the respondents in the language knowledge tests, both in native and second languages.

3. Grade Transmutation - This procedure was used to compute for the equivalent grades of the respondents' scores in the tests. This is adapted from the formula used by the Department of Education to determine the transmuted grade of students.

4. Pearson Product Moment Correlation Coefficient - This statistical tool was used to determine the strength of the relationship between the independent and dependent variables, which are the Meranaw language performance and English language performance, respectively. This was also used to infer whether or not the independent variable has a causative role towards the dependent variable.

5. $t$-test for Pearson $\mathrm{r}$ - This inferential statistical tool was used to determine the significance of the relationship between the independent and dependent variables.

\section{Performance of the Respondents in Meranaw}

\section{RESULTS AND DISCUSSION}

Table 1. Performance of the Respondents in the Meranaw language in terms of Synonyms (Melagid sa maana)

\begin{tabular}{|c|c|c|c|c|c|}
\hline \multicolumn{6}{|c|}{ Synonyms (Melagid sa maana) } \\
\hline Raw Score & Transmuted Score & Frequency & Percent & Descriptive Rating & Mean Score/Rating \\
\hline 10 & 100 & 25 & 17.0 & Excellent & \multirow{8}{*}{ 91.84/Good } \\
\hline 9 & 95 & 56 & 38.1 & Very Good & \\
\hline 8 & 90 & 36 & 24.5 & Good & \\
\hline 7 & 85 & 14 & 9.5 & Fair/Satisfied & \\
\hline 6 & 80 & 11 & 7.5 & Passing & \\
\hline 5 & 75 & 4 & 2.7 & Passing & \\
\hline 4 & 70 & 1 & 0.7 & Failed & \\
\hline \multicolumn{2}{|r|}{ Total } & 147 & \multicolumn{2}{|r|}{100} & \\
\hline
\end{tabular}

98 \& above - Excellent; 93-97 - Very Good; 87-92 - Good; 81-86 - Fair/Satisfactory; 75-80 Passing; 74 \& below - Failed

Table 1 shows the performance of the respondents in the Meranaw language in terms of synonyms. The result shows that out of 147 respondents, $1(0.7 \%)$ got a failing grade with a raw score of 4 and transmuted score of 70; 4 (2.7\%) got a passing grade with a raw score of 5 and transmuted score of 75; while $11(7.5 \%)$ got a passing grade with a raw score of 6 and transmuted score of 80 . Moreover, there were $14(9.5 \%)$ who got a satisfactory grade with a raw score of 7 and transmuted score of $85 ; 36$ (24.5\%) got good grade with a raw score of 8 
and transmuted score of 90 ; while $56(38.1 \%)$ got a very good grade with a raw score of 9 and transmuted score of 95. Lastly, $25(17.0 \%)$ respondents got an excellent grade with a raw score of 10 and transmuted score of 100.

In the table shown above, the mean grade is 91.84 described as good. It indicates that a good rating is the average performance of the majority of the respondents. In addition, almost all of the students passed the synonym test in the Meranaw language. This finding is a glaring fact that the respondents have already developed proficiency in their native language, especially on the identifying the synonymous terms of Meranaw words. Leaning on behaviorists' principle, for a number of years being exposed to a Meranaw society, where people speak the Meranaw language especially the family members, it is already an assurance that they are able to use the language in different ways such as for speaking, writing, and even for comprehending. Moreover, nurture and nature may also have influences to this ability they have.

Table 2. Performance of the Respondents in the Meranaw Language in terms of Antonyms (Mebida sa Maana)

\begin{tabular}{|c|c|c|c|c|c|}
\hline \multicolumn{6}{|c|}{ Antonyms (Mebida sa Maana) } \\
\hline Raw Score & Transmuted Score & Frequency & Percent & Descriptive Rating & Mean Score/Rating \\
\hline 10 & 100 & 4 & 2.7 & Excellent & \multirow{12}{*}{ 75.41/ Passing } \\
\hline 9 & 95 & 1 & 0.7 & Very Good & \\
\hline 8 & 90 & 7 & 4.8 & Good & \\
\hline 7 & 85 & 19 & 12.9 & Fair/Satisfied & \\
\hline 6 & 80 & 27 & 18.4 & Passing & \\
\hline 5 & 75 & 37 & 25.2 & Passing & \\
\hline 4 & 70 & 24 & 16.3 & Failed & \\
\hline 3 & 65 & 20 & 13.6 & Failed & \\
\hline 2 & 60 & 2 & 1.4 & Failed & \\
\hline 1 & 55 & 2 & 1.4 & Failed & \\
\hline 0 & 50 & 4 & 2.7 & Failed & \\
\hline Total & & 147 & 100 & Failed & \\
\hline
\end{tabular}

98 \& above - Excellent; 93-97 - Very Good; 87-92 - Good; 81-86 - Fair/Satisfactory; 75-80 Passing; 74 \& below - Failed

Table 2 shows the performance of the respondents in the Meranaw language in terms of antonyms. This result shows that out of 147 respondents, $4(2.7 \%)$ got failed with a raw score of 0 and transmuted score of 50; 2 (1.4\%) got failed with a raw score of 1 and transmuted score of 55; 2 (1.4\%) also got failed with a raw score of 2 and transmuted score of 60; while 20 $(13.6 \%)$ got failed with a raw score of 3 and transmuted grade of 65 . In addition, 24 (16.3\%) got failed with a raw score of 4 and transmuted grade of $70 ; 37(25.2 \%)$ got a passing rating with a raw score of 5 and transmuted score or $75 ; 27$ (18.4\%) got a passing grade with a raw score of 6 and transmuted score of 80; and 19 (12.9\%) got a fair or satisfactory rating with a raw score of 7 and transmuted grade of 85 . Finally, there were $7(4.8 \%)$ respondents who got a good rating with a raw score of 8 and transmuted score of $90 ; 1(0.7 \%)$ got a very good rating with a raw score of 9 and transmuted score of 95; and $4(2.7 \%)$ got an excellent rating with a raw score of 10 and transmuted score of 100 . The mean score is 75.41 , denoting that the average performance of the respondents in the test is passing.

However, it is surprising that there were respondents who still failed the Meranaw language test on antonyms. Unlike the previous result, this finding implies that some of the respondents still struggle to determine the opposite meanings of some Meranaw terms. This could be attributed to the difference in the process of attaining answers to this type of test. In synonyms, respondents just needed to determine what word is closest in meaning to the given words. Otherwise, in antonyms, respondents may need to determine first the synonymous words of 
the given words before they can determine the opposite of them. Thus, identifying the anonyms may be quite laborious compared to synonyms in terms of the process of identifying the answers, which may have caused them to get low scores.

Table 3. Performance of the Respondents in the Meranaw Language in terms of Contextual Clues (Meranaw)

\begin{tabular}{|c|c|c|c|c|c|}
\hline \multicolumn{5}{|c|}{ Contextual Clues (Meranaw) } \\
\cline { 1 - 5 } Raw Score & Transmuted Score & Frequency & Percent & Descriptive Rating & Mean Score/Rating \\
\hline 5 & 100 & 52 & 35.4 & Excellent & \\
\cline { 1 - 5 } & 90 & 47 & 32 & Good & \multirow{2}{*}{ 88.64/Good } \\
\hline 3 & 80 & 33 & 22.4 & Passing & \\
\hline 2 & 70 & 10 & 6.8 & Failed & \\
\hline 1 & 60 & 1 & 0.7 & Failed & \\
\hline 0 & 50 & 4 & 2.7 & Failed & \\
\hline Total & & 147 & 100 & Failed & \\
\hline
\end{tabular}

98 \& above - Excellent; 93-97 - Very Good; 87-92 - Good; 81-86 - Fair/Satisfactory; 75-80 Passing; 74 \& below - Failed

Table 3 shows the performance of the respondents in the Meranaw language in terms of contextual clues. It shows that out of 147 respondents, $4(2.7 \%)$ of them failed with a raw score of 0 and transmuted score of 50; $1(0.7 \%)$ failed with a raw score of 1 and transmuted score of 60 ; and $10(6.8 \%)$ failed with a raw score of 2 and transmuted score of 70 . Moreover, 33 $(22.4 \%)$ respondents got a passing rate with a raw score of 3 and transmuted score of $80 ; 47$ $(32 \%)$ got a good rating with a raw score of 4 and transmuted score of 90 ; while 52 (35.4\%) got an excellent rating with a raw score of 5 and transmuted score of 100 . Given with the mean score of 88.64, it can be construed that the average performance of the respondents in the test for contextual clues is good.

This finding is quite commendable since a great majority passed and even performed well in the test. However, there were still those who are not successful in passing the test in Meranaw language contextual clues. It may imply that their ability to extract clues to determine the meaning of some unfamiliar Meranaw terms is still undeveloped and insufficient.

\section{Performance of the Respondents in English}

Table 4. Performance of the Respondents in English Language in terms of Synonyms

\begin{tabular}{|c|c|c|c|c|c|}
\hline \multicolumn{6}{|c|}{ Identifying Synonyms } \\
\hline Raw Score & Transmuted Score & Frequency & Percent & Descriptive Rating & Mean Score/Rating \\
\hline 10 & 100 & 26 & 17.7 & Excellent & \multirow{10}{*}{$88.50 /$ Good } \\
\hline 9 & 95 & 27 & 18.4 & Very Good & \\
\hline 8 & 90 & 38 & 25.9 & Good & \\
\hline 7 & 85 & 22 & 15 & Fair/Satisfied & \\
\hline 6 & 80 & 19 & 12.9 & Passing & \\
\hline 5 & 75 & 7 & 4.8 & Passing & \\
\hline 4 & 70 & 1 & 0.7 & Failed & \\
\hline 3 & 65 & 6 & 4.1 & Failed & \\
\hline 0 & 50 & 1 & 0.7 & Failed & \\
\hline Total & & 147 & 100 & & \\
\hline
\end{tabular}

98 \& above - Excellent; 93-97 - Very Good; 87-92 - Good; 81-86 - Fair/Satisfactory; 75-80 Passing; 74 \& below - Failed 
Table 4 shows the performance of the respondents in English language in terms of synonyms. It shows that out of 147 respondents, $1(0.7 \%)$ failed with a raw score of and transmuted score of 50; $6(4.1 \%)$ failed with a raw score of 3 and transmuted score of 65 ; and $1(0.7 \%)$ failed with a raw score of 4 and transmuted score of 70 . Moreover, 7 (4.8\%) respondents got a passing rating with a raw score of 5 and transmuted score of 75; 19 (12.9\%) got a passing grade with a raw score of 6 and transmuted score of 80; and $22(15 \%)$ got a fair/satisfactory grade with a raw score of 7 and transmuted grade of 85 . There were also 38 (25.9\%) respondents who got a good rating with a raw score of 8 and transmuted score of 90; 27 (18.4\%) got a very good rating with a raw score of 9 and transmuted score of 95; while 26 $(17.7 \%)$ got an excellent rating with a raw score of 10 and transmuted grade of 100 . As computed, the mean score of the respondents is 88.50 described as a good performance which means that the average performance of the majority was good.

This finding reveals that the respondents have possessed a considerable level of proficiency in English especially in determining the synonyms of certain unfamiliar words. However, there are more respondents who failed in English language test on synonyms compared to those who failed in the Meranaw synonyms test and the lowest score in the latter is 4 while in the former is 0 . This just means that they have a higher linguistic knowledge in their native language compared to their second language.

Table 5. Performance of the Respondents in English in terms of Antonyms

\begin{tabular}{|c|c|c|c|c|c|}
\hline \multicolumn{6}{|c|}{ Antonyms } \\
\hline Raw Score & Transmuted Score & Frequency & Percent & Descriptive Rating & Mean Score/Rating \\
\hline 10 & 100 & 2 & 1.4 & Excellent & \multirow{12}{*}{ 80.03/ Passing } \\
\hline 9 & 95 & 22 & 15 & Very Good & \\
\hline 8 & 90 & 25 & 17 & Good & \\
\hline 7 & 85 & 23 & 15.6 & Fair/Satisfied & \\
\hline 6 & 80 & 23 & 15.6 & Passing & \\
\hline 5 & 75 & 26 & 10.9 & Passing & \\
\hline 4 & 70 & 12 & 8.2 & Failed & \\
\hline 3 & 65 & 8 & 5.4 & Failed & \\
\hline 2 & 60 & 5 & 3.4 & Failed & \\
\hline 1 & 55 & 4 & 2.7 & Failed & \\
\hline 0 & 50 & 7 & 4.8 & Failed & \\
\hline Total & & 147 & 100 & & \\
\hline
\end{tabular}

98 \& above - Excellent; 93-97 - Very Good; 87-92 - Good; 81-86 - Fair/Satisfactory; 75-80 Passing; 74 \& below - Failed

Table 5 shows the performance of the respondents in English language in terms of antonyms. It shows that out of 147 respondents, 7 (4.8\%) failed with a raw score of 0 and transmuted score $50 ; 4(2.7 \%)$ failed with a raw score of 1 and transmuted score $55 ; 5$ (3.4\%) failed with a raw score of 2 and transmuted score 60 . There were also $8(5.4 \%)$ respondents who failed with a raw score of 3 and transmuted score 65 and $12(8.2 \%)$ failed as well with a raw score of 4 and transmuted score 70 . On the lighter note, $16(10.9 \%)$ got a passing rating with a raw score of 5 and transmuted score of $75 ; 23(15.6 \%)$ got fair or satisfactory rating with a raw score of 7 and transmuted score of 85; and 25 (17\%) got good rating with a raw score of 8 and transmuted score of 90 . Finally, $22(15 \%)$ respondents got very god rating with a raw score of 9 and transmuted score of 95 while $2(1.4 \%)$ got an excellent rating with a raw score of 10 and transmuted score of 100 . The computed mean score is 80.03 , which is lower than the previous test in synonyms, described as passing.

As compared to the previous result in synonym test, the mean score in antonym test is lower. But when this is compared to their mean score in Meranaw antonym test, this is quite better. 
This means that, even though the general average is passing, many of the respondents are still not proficient in determining the opposite meanings of some terms in the second language which is English. In fact, it is ironic to know that the more they are not proficient in Meranaw language antonyms especially that more respondents failed in the native language antonym test than in the English language.

Table 6. Performance of the Respondents in English Language in terms of Contextual Clues

\begin{tabular}{|c|c|c|c|c|c|}
\hline \multicolumn{6}{|c|}{ Contextual Clues } \\
\hline Raw Score & Transmuted Score & Frequency & Percent & Descriptive Rating & Mean Score/Grade \\
\hline 5 & 100 & 14 & 9.5 & Excellent & \multirow{7}{*}{ 78.23/Passing } \\
\hline 4 & 90 & 30 & 20.4 & Good & \\
\hline 3 & 80 & 46 & 31.3 & Passing & \\
\hline 2 & 70 & 35 & 23.8 & Failed & \\
\hline 1 & 60 & 17 & 11.6 & Failed & \\
\hline 0 & 50 & 5 & 3.4 & Failed & \\
\hline Total & & 147 & 100 & & \\
\hline
\end{tabular}

98 \& above - Excellent; 93-97 - Very Good; 87-92 - Good; 81-86 - Fair/Satisfactory; 75-80 Passing; 74 \& below - Failed

Table 6 shows the performance of the respondents in English language in terms of contextual clues. It shows that $5(3.4 \%)$ respondents failed with a raw score of 0 and transmuted score of $50 ; 17(11.6 \%)$ also failed with a raw score of 1 and a transmuted grade of 60 ; and $35(23.8 \%)$ failed as well with a raw score of 2 and transmuted score of 70. On the other hand, 36 (31.3\%) got a passing rating with a raw score of 3 and transmuted score of 80 while $30(20.4 \%)$ got a good rating with a raw score of 4 and transmuted score of 90. Lastly, 14 (9.5\%) got an excellent rating with a raw score of 5 and transmuted score of 100 . With a mean score of 78.23 , it can be inferred that the average performance of a greater number of respondents is passing.

This finding reveals that the respondents already have a certain level of proficiency in decoding meanings of unfamiliar English terms. However, this proficiency is still far from their proficiency in the Meranaw language. This can be accounted from the fact that they are still not totally familiar with the strategies in deciphering meanings form English language contexts since they are still on the process of enhancing their linguistic knowledge.

\section{Testing of Hypotheses}

Ho1: There is no significant relationship between the respondents' native language and their English language performance in terms of Synonyms.

Table 7. Relationship between the Respondents' Native language and their English Language Performance in terms of Synonyms

\begin{tabular}{|c|c|c|c|c|}
\hline Synonyms & Pearson's r & p-value & Interpretation & Decision \\
\cline { 1 - 5 } Native language & 0.306 & 0.000 & Significant & Reject $\mathrm{Ho}_{1}$ \\
\hline English language acquisition & &
\end{tabular}

To find significant relationship between respondents' native language and their English language acquisition in terms of synonyms, the test statistic used was the Pearson's $r$. Based on the table above, the value of the correlation coefficient $(r)$ is 0.306 which entails weak positive correlation between the two variables. This means that their linguistic knowledge in Meranaw synonyms has a positive role towards their English language acquisition. Despite its weak causative role, the $p$-value 0.000 which is less than $\alpha=0.05$ level of significance, clearly indicates that their relationship is significant. Therefore, together with other unidentified variables, native language has a significant effect to respondents' English language acquisition 
particularly in determining words that are synonymous to certain unfamiliar words. This means that the first null hypothesis is rejected.

Ho2: There is no significant relationship between the respondents' native language and their English language performance in terms of Antonyms.

Table 8. Relationship between the Respondents' Native Language and their English Language Performance in terms of Antonyms

\begin{tabular}{|c|c|c|c|c|}
\hline Antonyms & Pearson's r & p-value & Interpretation & Decision \\
\cline { 1 - 2 } Native language & 0.261 & 0.001 & Significant & Reject $\mathrm{Ho}_{2}$ \\
\hline English language acquisition & & & & \\
\hline
\end{tabular}

In Table 8, the correlation analysis between the respondents' scores in the Meranaw language and English language antonym test. Based on the table above, the value of the correlation coefficient $(r)$ is 0.261 which is similarly means that a weak positive correlation exists between the two variables. On the other hand, the $p$-value 0.001 is found to be less than $\alpha=0.05$, thus, their relationship is considered significant. It also reveals that linguistic knowledge in terms of antonyms in the Meranaw language significantly facilitates the linguistic knowledge in terms of antonym in the English language. Sufficient evidence proving the significant relationship between L1 and L2, particularly in identifying opposing meanings of words, has been found. So that, the second null hypothesis is rejected.

Ho $_{3}$ There is no significant relationship between respondents' native language and their English language performance in terms of Contextual Clues.

Table 9. Relationship between the Respondents' Native language and their English Language Performance in terms of Contextual Clues

\begin{tabular}{|c|c|c|c|c|}
\hline Contextual Clues & Pearson's r & p-value & Interpretation & Decision \\
\hline Native language & 0.186 & 0.024 & Significant & Reject $\mathrm{Ho}_{3}$ \\
\hline English language acquisition & & &
\end{tabular}

Table 9 presents the results of the correlation analysis between the respondents Meranaw language and English language performance in the contextual clues test. According to the data shown, the value of the correlation coefficient $(r)$ is 0.186 ; meaning, there is a weak positive correlation existing between the two variables. However, with a $p$-value of 0.024 which is less than $\alpha=0.05$, it is still found that their weak relationship is significant. It denotes that native language proficiency in contextual clues is one of the variables having significant facilitating roles towards English language acquisition. Therefore, it is decided to reject the third null hypothesis.

After all the hypothesis tests, it was found out that in all tests-synonyms, antonyms, and contextual clues-the native language Meranaw has a weak but significant role in developing and facilitating English language acquisition and performance. This is a strong supporting evidence to the assertions of previous researchers that everything acquired in the first language (academic skills, literacy development, concept formation, subject knowledge, and learning strategies) will transfer to the second language. Meaning, children are using their background and experience they have available to them from their first language (Clark, n.d). Furthermore, it is also true that, according to Cook (2003), L1 and L2 are connected in the L2 user's mind, most particularly in vocabulary. To simply put, even though L1 and L2 are different in many ways, L1 linguistic knowledge is used by L2 learners as part of their comprehension processes. As what Tucker (2002), as cited by Gran and Plaza (2013), agreed to 
the development of the mother tongue is important for cognitive development and as a basis for learning the second language.

The researchers also conducted informal interviews with ten selected respondents and asked the question "Do you think your first language has a contribution to your English language learning process?" It turned out that most of them revealed the contribution of their first language in learning the English language. The result of the study was supported by Cummins' Linguistic Interdependence Hypothesis which argues that certain first language knowledge can be positively transferred during the process of second language acquisition. The L1 linguistic knowledge and skills that a child possesses can be extremely instrumental to the development of corresponding abilities in the L2.

\section{CONCLUSION AND RECOMMENDATIONS}

This study aimed to determine whether there is a significant relationship between Meranao language and English language in terms of vocabulary skills in synonyms, antonyms, and contextual clues. According to the data gathered, although weak positive correlations were found, still the association of the Meranao language to English language is significant. This just means that, with the rejection of all the null hypotheses, it is important to consider the role of the native language in the second language learning skills of students. This study confirmed this among fourth year high school students. Based on the data, there is a greater possibility that young L2 learners, especially those from Kindergarten to Grade 3, can acquire and be more proficient in the second language since they are expected to have developed proficiency in their first language after Grade 3. The teachers can now then capitalize from this fact and utilize this proficiency to facilitate in hastening the second language acquisition of students, specifically the English language. The K+12 curriculum and theoretical framework are, therefore, practically and realistically grounded with sufficient evidences that L1 can positively affect L2 learning.

In the light of these findings, the researchers have come up with the following recommendations. First, English teachers should therefore be aware of the growing trends regarding the important positive role of native language to second language acquisition, especially in the context of Marawi City in order for them to keep abreast with the development of teaching English as a second language. They must also consider attending pertinent trainings and seminars regarding the proper way of teaching English using the native language as an auxiliary or as a major medium of instruction inside the classroom. Moreover, they should exert more efforts in facilitating the second language acquisition process undergone by the students through employing effective approaches in teaching. Finally, they need to follow the implementing rules and regulations stipulated in the $\mathrm{K}+12$ curriculum, especially the teaching of English and the use of L1, to effectively help in realizing the goals of the state and the ideals of genuine education.

To further this research, future researchers should conduct similar studies regarding the role of L1 in the L2 acquisition, using larger sample size, a different research locale, more language test types, and other research methods. They may investigate further on the correlates of L2 acquisition, aside from the influence of L1 proficiency, such as the learners' profile, domains of exposure, and others. 


\section{References}

Ammon, U., Dittmar, N. \& Mattheier, K. (2006). Sociolinguistics: an international handbook of the science of language and society. Volume 3. Walter de Gruyter. p. 2018. ISBN 978-3-11-018418-1.

Anderson, J.C. (1984). Reading in a foreign language: a reading problem or a language problem. In J.C. Alderson and A.H. Urquhart (Eds.), Reading in a foreign language. (pp. 1-24). London: Longman.

Barrios, A. \& Bernardo, A. (2012). The Acquisition Case Marking by L1 Chabacano and L1 Cebuano Learners of L2 Filipino: Influence of Actancy Structure on Transfer. http://mlephil.files.wordpress.com/2010/03/theacquisition-of-case-marking-by-l1-chabacano-and-l1-cebuano-learners.doc

Bhela, B. (1999). International Education Journal Vol 1, No 1, 1999. "Native language interference in learning a second language: Exploratory case studies of native language interference with target language usage".

ehlt.flinders.edu.au/education/iej/articles/v1n1/bhela/bhela.pdf

Banerjee, N., Sinha, A. \& Shastri R. (2009). Interference of first language in the acquisition of second language. Journal of Psychology and Counseling, 1(7), 117-122.

Beardsmore, HB. (1982). Bilingualism: Basic principles. Tieto: Avon.

Bernhardt, E.B. \& Kamil, M.L. (1995). Interpreting relationships between L1 and L2 reading: consolidating the linguistic threshold and the linguistic interdependence hypotheses. Applied Linguistics, 16, 15-34.

Bismilla, V. (2010). Is there a place for students" mother tongue in college classrooms? Retrieved on September 12, 2012 www.centennialcollege.ca/Default.aspx?DN=8face487-ac1dd-42e9-afe1-1b2e1ff0a9d6.pdf

Blum-Kulka, S. \& Levenston, EA. (1983). Universals of lexical simplification, In Strategies in Interlanguage Communication, (eds), Faerch, C. and Kasper, G., Longman: London.

Bournot-Trites, M. \& Tallowitz, U. (2002). Report of current research on the effects of second language learning on first language literacy skills. Retrieved on August 2, 2012 from www.unbf.ca/L2/documents/reportofcurrentresearch.pdf

Bossers, B. (1991). On thresholds, ceilings and short-circuits: the relation between L1 reading, L2 reading, and L2 knowledge. In J.H. Hulstijn and J.F. Matter (Eds.), Reading in two languages: AILA review, 8, 45-60.

Brown, H.D. (2000). Principles of Language Learning and Teaching. (4th edn.) White Plains, NY: Addison Wesley Longman, Inc.

Brown, H.D. (1994). Principles of Language Learning and Teaching. (3rd edn.). Englewood Cliffs, NJ: Prentice Hall Regents.

Carrell, P.L. (1991). Second language reading: reading ability or language proficiency? Applied Linguistics, 12, 59179.

Carter, R. A. \& McCarthy M. J. (1988). Vocabulary and Language Teaching. London: Longman.

Clark, B (n.d). First- and Second-Language Acquisition in Early Childhood.

ecap.crc.illinois.edu/pubs/katzsym/clark-b.pdf

Chomsky, N. (1965). Aspects of the theory of syntax. Cambridge, MA: The MIT Press.

Cook, V. (2001). Second Language Learning and Language Teaching. (3rd edn.) New York: Oxford University Press.

Cook, V. (Ed). (2003). Effects of the second language on the first. Clevedon, UK: Multilingual Matters.

Cui, Y. (n.d.). L2 proficiency and L2 reading: consolidating the linguistic threshold hypothesis. Retrieved on November 20, 2012 from http://web.uvic.ca/ literacy/UVic language and literacy 2008 conference proceedings/15.L2 Proficiency and L2 Reading: consolidating the linguistic threshold hypothesis.pdf

Cummins, J. (1998). Negotiating identities: Education for empowerment in a diverse society. Los Angeles: California Association for Bilingual Education.

Cummins, J. (2000). Language, power and pedagogy: Bilingual children in the crossfire. Clevedon: Multilingual Matters. In M. Nikolov and B. Csapo, International Journal of Bilingualism.

Cummins, N., Miramontes, O. \& Nadeau, A. (1997). Restructuring Schools for Linguistic Diversity: Linking Decision Making to Effective Programs. USA: Teachers College Press.

Comrie, B. \& Redmond, W.A. (2008). “Language”. Microsoft Encarta 2009.

Dulay, H., Burt, M. \& Krashen S. (1982). Language two. New York: Oxford University Press. 
Guimba, M. D., Faisal, H. H. H., Madale-Unte, N. E., Guimba, W. D., \& Alico, J. C. (2019). Relationship Between Native Language And English Language Acquisition: The Case Of Meranaw Learners Of English. Advances in Social Sciences Research Journal, 6(1) $293-311$.

Dumatog, R.C. \& Dekker, D.E. (2003). First language education in Lubuagan, Northern Philippines. UNESCO Report.

Faerch, C. \& Kasper, G. (1983). Plans and strategies in foreign language communication. In Strategies in interlanguage communication, ed. C. Faerch and G. Kasper, Longman: London.

First Language. (n.d.). Retrieve on April 28, 2014 from

http://children.wandsworth.gov.uk/education/reu/Other/Reference/Definition of First Language.doc

Fry, C. (n.d.). Second Language Acquisition - Krashen and His Critics. Retrieved on November 30, 2012 from faculty.kfupm.edu.sa/PYP/fry/M4KRASH.pdf

Genesee, F. (1981). A comparison of early and late second language learning. Canadian Journal of Behavioural Science, $13,115-127$.

Gran, J.A. \& Plaza, R.A. (2013). Primary School Pupils' Perception on the Efficacy of Mother Tongue as Medium of Instruction in Burgos Elementary School. Undergraduate thesis. Mindanao State University

Hancin-Bhat, B. \& Durgonuglo, A. (1994). The Role of First Language in the Second-Language Reading Process. http://www.ideals.illinois.edu/bitstream/handle/2142/17731/ctrstreadtechrepv01992i00555_opt.pdf?sequenc e=1.Ipek, H. (2009). Comparing and contrasting first and second language acquisition: implications for language teachers. English Language Teaching, 2(2), 155-163.

Jiang, X. (2011). The role of first language literacy and second language proficiency in second language reading comprehension. The Reading Matrix 11(2).

Krashen, S. (1977). Age, rate, and eventual attainment in second language acquisition. TESOL Quarterly, 13, 573582.

Krashen, S.D. \& Terrell, T.D. (1981). The natural approach: Language acquisition in the classroom. London: Prentice Hall Europe.

Krashen, S. (1982). Theory versus practice in language training. In R. W. Blair (Ed.), Innovative approaches language teaching. Rowley, MA: Newburry House Publishers.

Krashen S. (1985). The input hypothesis: Issues and implications. Harlow: Longman.

Krashen, S.D. (2009). Principles and Practice. Retrieved on November 28, 2012 from www.sdkrashen.com/Principles_and_Practice/Principles_and_Practice.pdf

Krashen, S. \& Brown, C.L. (2007). What is academic language proficiency? Singapore Tertiary English Teachers Society.

Lee, J. \& Schalert, D.L. (1997). The relative contribution of L2 language proficiency and L1 reading ability to L2 reading performance; a test of the threshold hypothesis in an EFL context. TESOL Quarterly, 31, 713-739.

Lenneberg, E. (1967). Biological foundations of language. New York: Wiley.

Liu, J. (2008). L1 Use in L2 Vocabulary Learning: Facilitator or Barrier. International Education Studies, Vol. 1, No. 2. Retrieved on April 20, 2014 from www.ccsenet.org/hournal.html.

Mascara, S.A. (2012). Bilingualism: Extent of Practice among selected Faculty Members and Student's Language Proficiency in English and Filipino at MsU- UTC Main Campus. Undergraduate thesis. Mindanao State University.

McLaughlin, B. (1987). Reading in a second language: Studies with adult and child learners. In S.R. Goldman \& H.T. Trueba (Eds.), Becoming Literate in English as a Second Language. Norwood, NJ: Ablex Publishing.

Mayberry, R.I. \& Lock, E. (2003). Age constraints on first versus second language acquisition: evidence for linguistic plasticity and epigenesist. Brain and Language, 87, 369-384.

Meyer, H. (2008). The Pedagogical Implications of L1 Use in the L2 Classroom. Retrieved on November 19, 2012 from www.kyoai.ac.jp/college/ronshuu/no-08/meyer1.pdf

Microsoft Encarta. (2009). "Antonym".

Microsoft Encarta. (2009). "Contextual Clue".

Microsoft Encarta. (2009). "Synonym".

n.a. (2004). Center for Applied Linguistics. http://www.cal.org/resources/pubs/homelang eng.pdf

n.a. (2001). The Ontario Curriculum Grades 1-8 Native Languages. http://www.edu.gov.on.ca.

Nikolov, M. \& Csapo, B. (2010). The relationship between reading skills in early English as a foreign language and Hungarian as a first language. International Journal of Bilingualism, 14(3), 315-329. 
Nunnaly, J. \& Bernstein, I. (1999). Psychometric theory. New York: McGraw \& Hill.

Second Language. (n.d.). Retrieved on April 20, 2014 from

http://children.wandsworth.gov.uk/education/reu/Other/Reference/Definition of Second Language.doc

Shah, P., Yusof, A., Hamid, Z., Ghafar, S., Hashim, H., Abdullah, A. \& Sabri, A. (2010). Process of L1 acquisition: linguistic theory in application. Research Journal of International Studies, 14.

Taillefer, G.E. (1996). L2 reading ability: further insight into the short-circuit hypothesis. Modern Language Journal, 80, 4, 461-477.

The Literacy and Numeracy Secretariat. (2011). French immersion in Ontario. Capacity Building Series. Retrieved on August 8, 2012 from www.edu.gov.on.ca/eng/literacynumeracy/inspire/.

Yamashita, J. (2002). Mutual compensation between L1 reading ability and L2 language proficiency in L2 reading comprehension. Journal of Research in Reading, 25(1), 81-95. 